\title{
Plastic deformation in Ce-based bulk metallic glasses during depth-sensing indentation
}

\author{
B.C. Wei ${ }^{\text {a,* }}$, T.H. Zhang ${ }^{\text {b }}$, L.C. Zhang ${ }^{\text {a }}$, D.M. Xing ${ }^{\text {b }}$, W.H. Li ${ }^{\text {a }}$, Y. Liu ${ }^{\text {a }}$ \\ a National Microgravity Laboratory, Institute of Mechanics, Chinese Academy of Sciences, Beijing 100080, China \\ ${ }^{\mathrm{b}}$ State Key Laboratory of Nonlinear Mechanics (LNM), Institute of Mechanics, Chinese Academy of Sciences, Beijing 100080, China
}

Received 22 August 2005; received in revised form 15 November 2005; accepted 24 January 2006

\begin{abstract}
The deformation behavior and the effect of the loading rate on the plastic deformation features in (numbers indicate at.\%) $\mathrm{Ce}_{60} \mathrm{Al}_{15} \mathrm{Cu}_{10} \mathrm{Ni}_{15}$, $\mathrm{Ce}_{65} \mathrm{Al}_{10} \mathrm{Cu}_{10} \mathrm{Ni}_{10} \mathrm{Nb}_{5}, \mathrm{Ce}_{68} \mathrm{Al}_{10} \mathrm{Cu}_{20} \mathrm{Nb}_{2}$, and $\mathrm{Ce}_{70} \mathrm{Al}_{10} \mathrm{Cu}_{20}$ bulk metallic glasses (BMGs) were investigated through nanoindentation. The load-displacement $(P-h)$ curves of $\mathrm{Ce}_{65} \mathrm{Al}_{10} \mathrm{Cu}_{10} \mathrm{Ni}_{10} \mathrm{Nb}_{5}, \mathrm{Ce}_{68} \mathrm{Al}_{10} \mathrm{Cu}_{20} \mathrm{Nb}_{2}$, and $\mathrm{Ce}_{70} \mathrm{Al}_{10} \mathrm{Cu}_{20} \mathrm{BMGs}$ exhibited a continuous plastic deformation at all studied loading rate. Whereas, the $P-h$ curves of $\mathrm{Ce}_{60} \mathrm{Al}_{15} \mathrm{Cu}_{10} \mathrm{Ni}_{15} \mathrm{BMG}$ showed a quite unique feature, i.e. homogeneous plastic deformation at low loading rates, and a distinct serrated flow at high strain rates. Moreover, a creep deformation during the load holding segment was observed for the four Ce-based BMGs at room temperature. The mechanism for the appearance of the "anomalous" plastic deformation behavior in the Ce-based BMGs was discussed.
\end{abstract}

(C) 2006 Elsevier B.V. All rights reserved.

Keywords: Metallic glass; Mechanical property; Nanoindentation; Plastic deformation

\section{Introduction}

Bulk metallic glasses (BMGs) have shown potential as structural materials due to their exceptional mechanical properties. However, it is known that their room temperature ductility is limited due to a catastrophic failure resulting from shear localization. Understanding the micro-mechanisms of plastic deformation and developing the constitutive relationships for BMGs is an active area of research [1-7]. Recently, nanoindentation has been proposed as a key method for the study of localized deformation by shear banding in BMGs [5,8-14]. It is found that the character of serrated flow depends strongly on the composition and structure of BMGs, as well as the applied strain rate during nanoindentation measurements [9-11,14]. The Pd-based alloys exhibit sharper displacement bursts than for Zr-based materials at the same loading rate [9]. Schuh and co-workers constituted a new high-rate regime of homogeneous flow on the deformation map of metallic glasses $[5,9,10]$. They suggest that there is a transition in plastic flow behavior in which serrations are suppressed at higher strain rate.

\footnotetext{
* Corresponding author. Tel.: +86 1062614945 ; fax: +86 1062615524

E-mail address: weibc@imech.ac.cn (B.C. Wei).
}

More recently, Ce-based BMGs with an exceptionally low glass transition temperature $T_{\mathrm{g}}$ have been reported. These materials can be repeatedly shaped in near-boiling water, and can thus be regarded as "metallic plastics" $[15,16]$. There is a general trend for metallic glass that, as the testing temperature approaches $T_{\mathrm{g}}\left(T / T_{\mathrm{g}}>0.7\right)$, the deformation behavior changes gradually from inhomogeneous to homogeneous viscous flow [17-19]. The $T / T_{\mathrm{g}}$ values of the Ce-based BMGs are about 0.8 at room temperature [16]. This suggests that a homogeneous plastic deformation may occur in the Ce-based BMGs at room temperature. However, no distinct bulk plastic strain can be observed during the quasi-static state uniaxial compressive tests in Ce-based BMGs at room temperature [20], which indicates a strongly inhomogeneous deformation. For further understanding the plastic deformation mechanism in Ce-based BMGs, detailed study on the plastic deformation process is needed. In this work, the deformation behavior in four Ce-based BMGs is investigated by nanoindentation.

\section{Experimental procedure}

BMG plates with $2 \mathrm{~mm}$ in thickness of (numbers indicate at.\%) $\mathrm{Ce}_{60} \mathrm{Al}_{15} \mathrm{Cu}_{10} \mathrm{Ni}_{15}, \mathrm{Ce}_{65} \mathrm{Al}_{10} \mathrm{Cu}_{10} \mathrm{Ni}_{10} \mathrm{Nb}_{5}, \mathrm{Ce}_{68} \mathrm{Al}_{10}$ $\mathrm{Cu}_{20} \mathrm{Nb}_{2}$, and $\mathrm{Ce}_{70} \mathrm{Al}_{10} \mathrm{Cu}_{20}$ were prepared by melting pure 
metals in an argon atmosphere and then suction-casting in a copper mould. The structure of samples was characterized by X-ray diffraction (XRD) in a Philips PW 1050 diffractometer using $\mathrm{Cu} \mathrm{K} \alpha$ radiation. Differential scanning calorimetry (DSC) was performed with a Perkin-Elmer DSC-7 differential scanning calorimeter under argon atmosphere. A constant heating rate of $0.33 \mathrm{~K} / \mathrm{s}$ was employed. The specimens for nanoindentation measurements were mechanically polished to a mirror finish and tested in a MTS Nano Indenter ${ }^{\circledR}$ XP with a Berkovich diamond tip. A fused silica was used as a standard sample for the initial calibration. The indentations were performed in loadcontrol mode to a depth limit of $1 \mu \mathrm{m}$ using loading rates from 0.03 to $1.0 \mathrm{mN} / \mathrm{s}$. The thermal drift of the instrument was maintained below $0.05 \mathrm{~nm} / \mathrm{s}$. At least six indentations were made for each test on each specimen. All tests were carried out at $296 \mathrm{~K}$. The indentation segments include five subsequent steps: a constant loading rate segment at the given loading rate, holding at the maximum load for $10 \mathrm{~s}$, and then unloading to $10 \%$ of the maximum load, followed by another holding for $10 \mathrm{~s}$, and finally unloading completely.

\section{Results and discussion}

As-cast $\mathrm{Ce}_{60} \mathrm{Al}_{15} \mathrm{Cu}_{10} \mathrm{Ni}_{15}, \mathrm{Ce}_{65} \mathrm{Al}_{10} \mathrm{Cu}_{10} \mathrm{Ni}_{10} \mathrm{Nb}_{5}, \mathrm{Ce}_{68}$ $\mathrm{Al}_{10} \mathrm{Cu}_{20} \mathrm{Nb}_{2}$, and $\mathrm{Ce}_{70} \mathrm{Al}_{10} \mathrm{Cu}_{20}$ alloys exhibit $\mathrm{XRD}$ spectrum typical for amorphous phase without obvious crystalline peak. Fig. 1 illuminates the DSC traces of the four alloys at a constant scanning rate of $0.33 \mathrm{~K} / \mathrm{s}$. The onset temperature of the glass transition $\left(T_{\mathrm{g}}\right)$, the crystallization temperature $\left(T_{\mathrm{x}}\right)$, and supercooled liquid region $\left(\Delta T_{\mathrm{x}}=T_{\mathrm{x}}-T_{\mathrm{g}}\right)$ for the four BMGs are listed in Table 1. These values agree with the results in ref. [16]. $\mathrm{Ce}_{60} \mathrm{Al}_{15} \mathrm{Cu}_{10} \mathrm{Ni}_{15} \mathrm{BMG}$ exhibits a relative higher $T_{\mathrm{g}}$ of $410 \mathrm{~K}$, while the latter three BMGs show similar $T_{\mathrm{g}}$ from 355 to $359 \mathrm{~K}$. The ratio of $T / T_{\mathrm{g}}$ ( $T$ is room temperature) for the four Ce-based BMGs is $0.72,0.83,0.82$, and 0.83 , respectively.

Typical load-displacement $(P-h)$ curves for nanoindentations on each of the four BMGs at various loading rates are presented in Fig. 2. The origin of each curve has been displaced for clearer observation. It can be seen that the deformation behavior in the four Ce-based BMGs is strongly dependent on

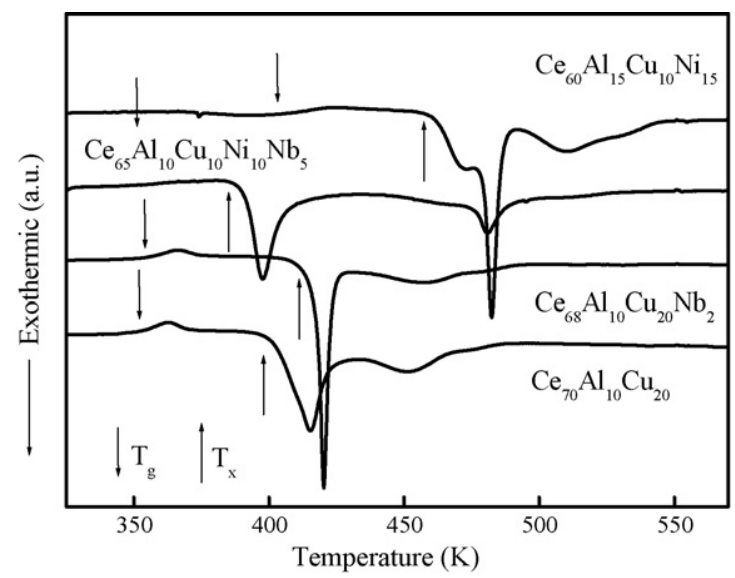

Fig. 1. DSC curves for the as-cast four BMGs.
Table 1

The onset temperature of the glass transition $\left(T_{\mathrm{g}}\right)$, the crystallization temperature $\left(T_{\mathrm{x}}\right)$, supercooled liquid region $\left(\Delta T_{\mathrm{x}}=T_{\mathrm{x}}-T_{\mathrm{g}}\right)$, and $T / T_{\mathrm{g}}$ ( $T$ is room temperature) for the four Ce-based BMGs

\begin{tabular}{lllll}
\hline Composition & $T_{\mathrm{g}}$ & $T_{\mathrm{x}}$ & $\Delta T_{\mathrm{x}}$ & $T / T_{\mathrm{g}}$ \\
\hline $\mathrm{Ce}_{60} \mathrm{Al}_{15} \mathrm{Cu}_{10} \mathrm{Ni}_{15}$ & 410.3 & 460.3 & 50 & 0.72 \\
$\mathrm{Ce}_{65} \mathrm{Al}_{10} \mathrm{Cu}_{10} \mathrm{Ni}_{10} \mathrm{Nb}_{5}$ & 355.2 & 389.1 & 33.9 & 0.83 \\
$\mathrm{Ce}_{68} \mathrm{Al}_{10} \mathrm{Cu}_{20} \mathrm{Nb}_{2}$ & 359.1 & 412.2 & 53.1 & 0.82 \\
$\mathrm{Ce}_{70} \mathrm{Al}_{10} \mathrm{Cu}_{20}$ & 356.9 & 400.6 & 43.7 & 0.83 \\
\hline
\end{tabular}

the indentation loading rate. $\mathrm{Ce}_{60} \mathrm{Al}_{15} \mathrm{Cu}_{10} \mathrm{Ni}_{15}$ BMG exhibits a smooth loading curve at low loading rates and a pronounced serrated flow at high loading rates (Fig. 2(a)). While for $\mathrm{Ce}_{65} \mathrm{Al}_{10} \mathrm{Cu}_{10} \mathrm{Ni}_{10} \mathrm{Nb}_{5}, \mathrm{Ce}_{68} \mathrm{Al}_{10} \mathrm{Cu}_{20} \mathrm{Nb}_{2}$, and $\mathrm{Ce}_{70} \mathrm{Al}_{10} \mathrm{Cu}_{20}$ $\mathrm{BMGs}$, the smooth deformation without distinct serrations is observed at all the studied loading rates (Fig. 2(b-d)). The threshold loading rate value for the appearance of the serrated flow during indentation in $\mathrm{Ce}_{60} \mathrm{Al}_{15} \mathrm{Cu}_{10} \mathrm{Ni}_{15}$ BMG is about $0.2 \mathrm{mN} / \mathrm{s}$. This deformation feature during nanoindentation is in contrast to that of other BMGs systems, e.g. Zr-, Pd-, and Mg-based BMGs, in which a low indentation rate promotes more pronounced serrations, and rapid indentation suppresses serrated flow.

It can also be found in Fig. 2 that the maximum load at the indentation depth of $1000 \mathrm{~nm}$ increases with increasing loading rate in the four BMGs. This means the hardness of the Ce-based BMGs is strongly dependent on the loading rate. The dependence of the hardness on the loading rate in the four BMGs is illuminated in Fig. 3. The hardness of $\mathrm{Ce}_{60} \mathrm{Al}_{15} \mathrm{Cu}_{10} \mathrm{Ni}_{15} \mathrm{BMG}$ is higher than that of the other three BMGs at all the loading rates. Its value increases gradually from $1.75 \mathrm{GPa}$ at $0.03 \mathrm{mN} / \mathrm{s}$ to $2.45 \mathrm{GPa}$ at $1.0 \mathrm{mN} / \mathrm{s}$. The hardness values at various loading rates are similar for $\mathrm{Ce}_{65} \mathrm{Al}_{10} \mathrm{Cu}_{10} \mathrm{Ni}_{10} \mathrm{Nb}_{5}, \mathrm{Ce}_{68} \mathrm{Al}_{10} \mathrm{Cu}_{20} \mathrm{Nb}_{2}$, and $\mathrm{Ce}_{70} \mathrm{Al}_{10} \mathrm{Cu}_{20} \mathrm{BMGs}$, and increase gradually from about $1.35 \mathrm{GPa}$ at $0.03 \mathrm{mN} / \mathrm{s}$ to $1.8 \mathrm{GPa}$ at $1.0 \mathrm{mN} / \mathrm{s}$.

It should be noted from the deformation behavior during nanoindentation (Fig. 2) that during the hold segment for $10 \mathrm{~s}$ at the maximum load, a creep displacement could clearly be observed in the four BMGs. The magnitude of creep displacement depends on the loading rate and the chemical compositions of the four BMGs. Higher loading rates promote larger creep displacement in all the four BMGs. At the same loading rate, $\mathrm{Ce}_{60} \mathrm{Al}_{15} \mathrm{Cu}_{10} \mathrm{Ni}_{15} \mathrm{BMG}$ exhibits a smaller creep displacement than that of the other three BMGs, e.g. at $0.03 \mathrm{mN} / \mathrm{s}$, $\mathrm{Ce}_{60} \mathrm{Al}_{15} \mathrm{Cu}_{10} \mathrm{Ni}_{15}$ BMG exhibits a creep displacement of about $18 \mathrm{~nm}$, while the other three BMGs show a similar value of about $28 \mathrm{~nm}$.

Generally, homogeneous deformation in metallic glasses usually takes place at high temperatures $\left(>0.70 T_{\mathrm{g}}\right)$, in contrast to inhomogeneous deformation at ambient temperature. The deformation behavior of BMGs near $T_{\mathrm{g}}$ can be Newtonian or nonNewtonian, depending upon testing temperature and strain rate [17-19,21]. Kawamura et al. [21], Chen et al. [22], and Nieh et al. [23] have reported a yield drop phenomenon during compressive experiment near $T_{g}$ in $\mathrm{Zr}$ - and Pd-based BMGs. That is, the flow stress $(\sigma)$, increases initially attaining a maximum $\left(\sigma_{\text {yield }}\right)$, then 

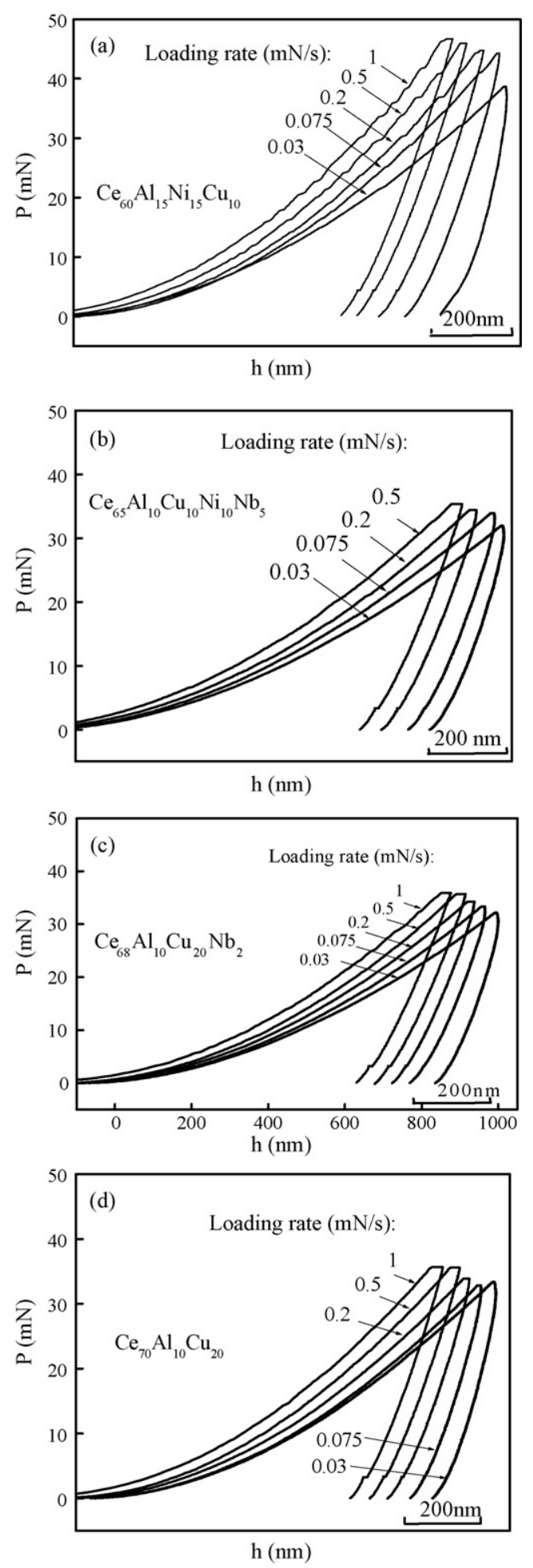

Fig. 2. Typical load-displacement $(P-h)$ curves during nanoindentations at various loading rate for $\mathrm{Ce}_{60} \mathrm{Al}_{15} \mathrm{Cu}_{10} \mathrm{Ni}_{15}$ (a), $\mathrm{Ce}_{65} \mathrm{Al}_{10} \mathrm{Cu}_{10} \mathrm{Ni}_{10} \mathrm{Nb}_{5}$ (b), $\mathrm{Ce}_{68} \mathrm{Al}_{10} \mathrm{Cu}_{20} \mathrm{Nb}_{2}$ (c), and $\mathrm{Ce}_{70} \mathrm{Al}_{10} \mathrm{Cu}_{20}$ (d) BMGs.

decreases and attains a steady-state flow value $\left(\sigma_{\text {flow }}\right)$. The magnitude of the yield drop $\left(\Delta \sigma=\sigma_{\text {yield }}-\sigma_{\text {flow }}\right)$ depends strongly on the temperature and the strain rate. In a constant strain-rate test, $\Delta \sigma$ shows a higher value at relatively low temperatures or high strain rates. The $T / T_{\mathrm{g}}$ values of the present Ce-based BMGs

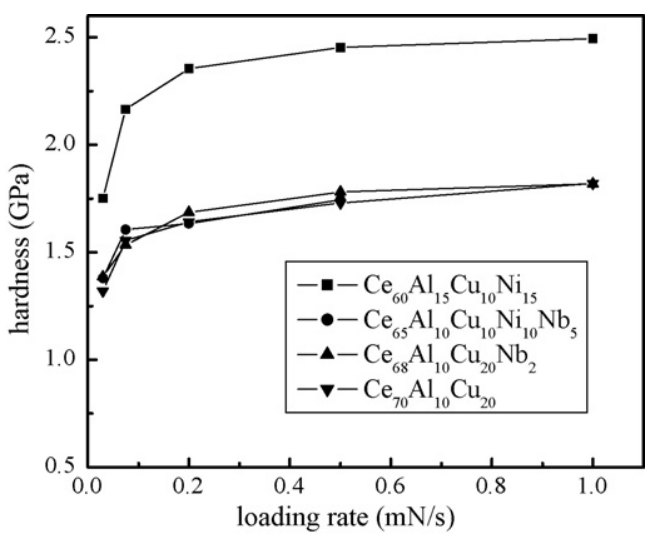

Fig. 3. Loading rate dependence of hardness in the four BMGs

are higher than 0.7 , thus the homogeneous flow may occur at room temperature. The appearance of the creep displacement during the nanoindentation measurement at room temperature should be related to the viscous flow of these BMGs. The creep displacement is strongly correlated to the loading time. At higher loading rates, the creep deformation is suppressed during the loading process and occurs mainly during the load-holding segment at the maximum load. While as at the lower loading rates, the creep occurs mainly during the loading process. As a result, the creep displacement decreases with the increasing loading rate (Fig. 2). The loading rate dependence of the hardness in the present Ce-based BMGs is also related to the creep process. During indentation at lower loading rates, the loading process is accompanied by the creep deformation. Thereby, the maximum load needed to attain the designed indentation depth is lower at the lower loading rates, due to the large creep deformation during the loading segment. That is, a lower hardness will be observed at the lower loading rates (Figs. 2 and 3).

The appearance of the serrated flow in $\mathrm{Ce}_{60} \mathrm{Al}_{15} \mathrm{Cu}_{10} \mathrm{Ni}_{15}$ BMG at high loading rates may be related to the yield drop phenomenon. The magnitude of the serrations increases with increasing loading rate due to the higher $\Delta \sigma$ at the higher loading rates [21-23]. The reason for the disappearance of serrated flow in the other three BMGs may due to their much higher $T / T_{\mathrm{g}}$ values, where $\Delta \sigma$ is less prominent. It must be pointed that the creep deformation of the present Ce-based BMGs is quite limited even at the highest loading rate (Fig. 2). In addition, the total of the width of each serration is much higher than the creep displacement. This indicates that the viscous flow is not the primary mechanism during plastic deformation. For further understanding the plastic deformation mechanism in these BMGs, the strain rate sensitivity coefficient $(m)$ of the four BMGs during indentation is evaluated, which is definited as:

$m=\frac{\Delta \log \sigma}{\Delta \log \dot{\varepsilon}}$

where $\sigma$ is the stress and $\dot{\varepsilon}$ is the strain rate. The slope of the double logarithm plots of the experimental points is $m$. The $m$ value of $\mathrm{Ce}_{60} \mathrm{Al}_{15} \mathrm{Cu}_{10} \mathrm{Ni}_{15}, \mathrm{Ce}_{65} \mathrm{Al}_{10} \mathrm{Cu}_{10} \mathrm{Ni}_{10} \mathrm{Nb}_{5}$, $\mathrm{Ce}_{68} \mathrm{Al}_{10} \mathrm{Cu}_{20} \mathrm{Nb}_{2}$, and $\mathrm{Ce}_{70} \mathrm{Al}_{10} \mathrm{Cu}_{20}$ BMGs is $0.075,0.085$, 0.077 , and 0.053 , respectively. If $m=1$, the flow is Newtonian; 
$m<1$ indicates inhomogeneous non-Newtonian flow [17]. This quite low $m$ values suggest that the plastic deformation of the $\mathrm{Ce}$ based BMG during nanoindentation is highly inhomogeneous, localized in the shear bands. This is proved by the direct observation of the plastic deformation region under the indent, which exhibits a well-developed shear band pattern for all the four BMGs [20]. Therefore, the plastic deformation behavior during nanoindentation at room temperature should be closely related to the nucleation and propagation of the shear bands. The prominent serrated flow of $\mathrm{Ce}_{60} \mathrm{Al}_{15} \mathrm{Cu}_{10} \mathrm{Ni}_{15} \mathrm{BMG}$ at high loading rates may be caused by the formation of smaller amount of shear bands with larger upset size [20]. For the other three BMGs, the disappearance of serrated flow at all loading rates may due to their quite low $T_{\mathrm{g}}$ and the localized viscous flow. As shown in Fig. 2, the later three BMGs exhibit a much larger creep displacement than that in $\mathrm{Ce}_{60} \mathrm{Al}_{15} \mathrm{Cu}_{10} \mathrm{Ni}_{15} \mathrm{BMG}$. The creep of metallic glass is related to the viscous flow of the materials. The more prominent viscous flow in the Ce-based BMGs with lower $T_{\mathrm{g}}$ could accommodate the stiff displacement caused by the propagation of the shear bands, thus lead to the disappearance of serrations.

\section{Conclusions}

The deformation behavior and the effect of the loading rate on the plastic deformation features in four Ce-based bulk metallic glasses were investigated through nanoindentation at room temperature. All the BMGs exhibit a loading rate dependence of hardness, and a distinct creep displacement during the load holding segment. $\mathrm{Ce}_{65} \mathrm{Al}_{10} \mathrm{Cu}_{10} \mathrm{Ni}_{10} \mathrm{Nb}_{5}, \mathrm{Ce}_{68} \mathrm{Al}_{10} \mathrm{Cu}_{20} \mathrm{Nb}_{2}$, and $\mathrm{Ce}_{70} \mathrm{Al}_{10} \mathrm{Cu}_{20}$ BMGs exhibit a smooth plastic deformation at all studied loading rate during indentation. Whereas, $\mathrm{Ce}_{60} \mathrm{Al}_{15} \mathrm{Cu}_{10} \mathrm{Ni}_{15}$ BMG shows a continuous plastic deformation at low loading rates, and a distinct serrated flow at high strain rates. Shear banding is the primary plastic deformation mechanism in the Ce-based BMGs, though the ratio of room temperature to $T_{\mathrm{g}}$ is lager than 0.7 for all of the studied alloys.

\section{Acknowledgements}

The authors would like to acknowledge the financial support provided by National Nature Science Foundation of China (Grant Nos. 50571109, 10572142, and 10432050) and the Knowledge Innovation Program of Chinese Academy of Sciences.

\section{References}

[1] C.C. Hays, C.P. Kim, W.L. Johnson, Phys. Rev. Lett. 84 (2000) 2901.

[2] G. He, J. Eckert, W. Löser, M. Hagiwara, Acta Mater. 52 (2003) 3035.

[3] K.M. Flores, R.H. Dauskardt, Intermetallics 12 (2004) 1025.

[4] H. Ma, J. Xu, E. Ma, Appl. Phys. Lett. 83 (2003) 2793

[5] C.A. Schuh, T.G. Nieh, J. Mater. Res. 19 (2004) 46.

[6] A. Inoue, Acta Mater. 48 (2000) 279.

[7] J. Li, F. Spaepen, T.C. Hufnagel, Philos. Mag. A 82 (2002) 2623.

[8] J.J. Kim, Y. Choi, S. Surech, A.S. Argon, Science 295 (2002) 654

[9] C.A. Schuh, T.G. Nieh, Acta Mater. 51 (2003) 87.

[10] T.G. Nieh, C. Schuh, J. Wadsworth, Y. Li, Intermetallics 10 (2002) 1177

[11] W.H. Jiang, M. Atzmon, J. Mater. Res. 18 (2003) 755.

[12] A.L. Greer, I.T. Walker, Mater. Sci. Forum 77 (2002) 386.

[13] B.C. Wei, T.H. Zhang, W.H. Li, Y.F. Sun, Y. Yu, Y.R. Wang, Intermetallics 12 (2004) 1239.

[14] C.A. Schuh, A.C. Lund, T.G. Nieh, Acta Mater. 52 (2004) 5879.

[15] B. Zhang, D.Q. Zhao, M.X. Pan, W.H. Wang, A.L. Greer, Phys. Rev. Lett. 94 (2005) 205502.

[16] B. Zhang, R.J. Wang, D.Q. Zhao, M.X. Pan, W.H. Wang, Phys. Rev. B 70 (2004) 224208.

[17] F. Spaepan, Acta Metall. 25 (1979) 407

[18] A.S. Argon, Acta Metall. 27 (1979) 47.

[19] C.A. Pampillo, J. Mater. Sci. 10 (1975) 1194.

[20] L.C. Zhang, T.H. Zhang, D.M. Xing, B.C. Wei, unpublished work.

[21] Y. Kawamura, T. Shibata, A. Inoue, Appl. Phys. Lett. 71 (1997) 779-781.

[22] H.S. Chen, H. Kato, A. Inoue, Mater. Trans. JIM 42 (2001) 597-605.

[23] T.G. Nieh, J. Wadsworth, C.T. Liu, T. Ohkubo, Y. Hirotsu, Acta Mater. 49 (2001) 2887-2896. 